\title{
O iluminador do Teatro Álvaro de Carvalho e do Teatro Ilhéu
}

\section{The illuminator of the Álvaro de Carvalho Theater and of the Illhéu Theater}

Entrevista com Carlos Falcão concedida à Ivo Godois ${ }^{1}$ 


\section{Resumo}

Entrevista realizada com o iluminador catarinense Carlos Falcão, em 04 de outubro de 2017, no Centro de Artes, da Universidade do Estado de Santa Catarina (UDESC), durante o evento Luz em Cena - 2017. Esta entrevista é um reconhecimento do valor deste iluminador para a história do teatro catarinense e do Teatro Álvaro de Carvalho em particular.

Palavras-chave: Iluminador; catarinense; aprendizado da iluminação

\section{Abstract}

Interview held with the illuminator Carlos Falcon, on October 4, 2017, at the Arts Center, the University of Santa Catarina State (UDESC), during the light event on scene - 2017. This interview is a recognition of the value of this illuminator for the history of the Santa Catarina Theatre and the Álvaro de Carvalho Theatre in special.

Keywords: Illuminator; Santa Catarina; lighting learning

ISSN: 1414.5731

E-ISSN: 2358.695

${ }^{1}$ Mestre em Teatro pelo Programa de Pós-Graduação em Teatro (PPGT), da Universidade do Estado de Santa Catarina (UDESC). Técnico em lluminação do Departamento de Artes Cênicas, do Centro de Artes (UDESC). ivogodo@gmail.com 


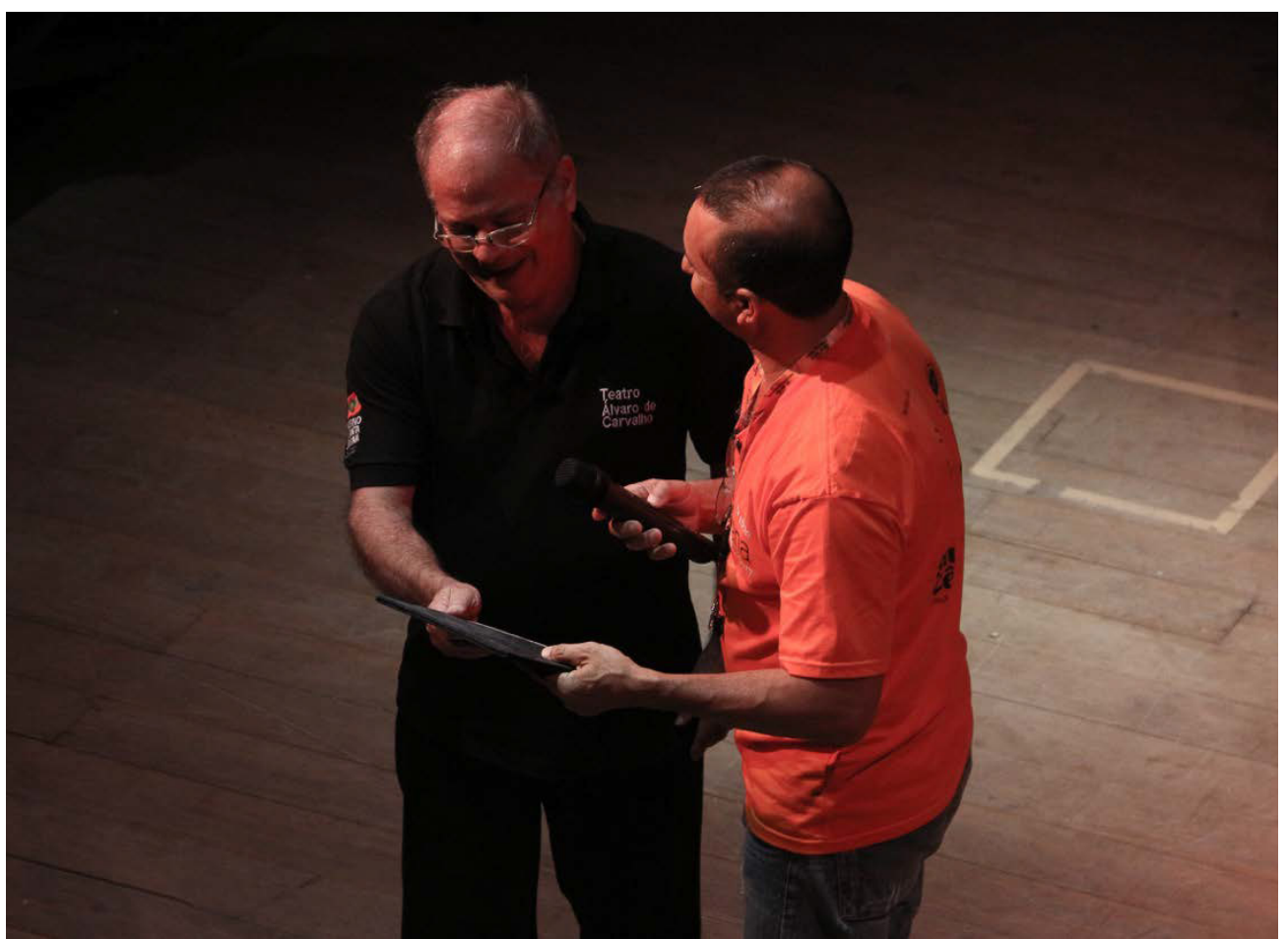

Carlos Falcão sendo homenageado por Ivo Godois no Luz em Cena 2017, pela relevância de seu trabalho para a iluminação cênica em Santa Catarina. Centro de Artes. Universidade do Estado de Santa Catarina (UDESC). Foto: Jerusa Mary.

Carlos António Falcão Cavalcante Linz é natural de São Francisco do Sul, cidade litorânea do norte catarinense. Nasceu em 20 de julho de 1952. Depois de cumprir um ano de convocação na Marinha, desembarcou em Florianópolis em busca de estudos e de emprego. No ano de 1979, Falcão estava cursando Engenharia Elétrica, na Universidade Federal de Santa Catarina. Ao sair pela cidade para procurar trabalho e manter-se estudando, estava ele no balcão de uma loja de materiais elétricos em busca de contatos para trabalhar, deparou-se com um conhecido e após apresentar-se e dispor-se a trabalhar, recebeu convite para uma pequena função, ou seja, de troca das lâmpadas dos lustres do Teatro Alvaro de Carvalho (TAC) ${ }^{2}$.

A história da aprendizagem técnica em especial da iluminação cênica no Teatro Álvaro de Carvalho e por extensão no estado catarinense está interligada com a história de Carlos Falcão. Conhecido popularmente por seu sobrenome, ou seja, "Falcão" e carinhosamente chamado como o "pai de todos", pelos mais experientes iluminadores da cidade, pois com ele foram iniciados no oficio de iluminação ${ }^{3}$.

A formação técnica e artística, de Carlos Falcão, se deu pela observação do trabalho de grandes mestres da iluminação que passaram pelo TAC no início da década de 1980. Profissionais como Jorginho de Carvalho, Aurélio de Simoni, Luiz Paulo Nenen e Beto Bruel. Carlos Falcão além de atender aos profissionais que se apresentavam no TAC, também trabalhou com inúmeros grupos teatrais locais, em cujos espetáculos ele criava e quase sempre executava a luz.

A entrevista aqui apresentada concede um espaço ao "professor", técnico e artista da luz, expondo sua visão de sua arte da qual ele foi um mestre propulsor no estado.

[...] como se deu a apropriação e disseminação do conhecimento técnico de ilu-

\footnotetext{
${ }^{2}$ Ivo Godois. UM PALCO ILUMINADO: O Teatro Álvaro de Carvalho em Florianópolis - SC - Década de 1980. Dissertação (Mestrado em Teatro). Programa de Pós-Graduação em Teatro (PPGT), Universidade do Estado de Santa Catarina. Florianópolis, p. 108, 2011.

${ }^{3}$ Ivo Godois, 2011, p. 107.
} 
minação, na década de 1980, no Teatro Álvaro de Carvalho [... se percebe] que um dos elementos centrais desse capítulo é a figura do iluminador Carlos Falcão, procurei acrescentar dados e argumentos, enfatizando a sua pessoa como chave no processo de ramificação do aprendizado da iluminação e disseminarão desse conhecimento em Florianópolis, bem como no estado de Santa Catarina, ao longo da década [1980].

A fala acima expõe os aspectos artesanais e do aprendizado do profissional e artista da luz no passado e ainda nos dias atuais no Brasil.

A aprendizagem das funções técnicas, no teatro brasileiro, não ocorria e, ainda em sua maioria, não ocorrem através de ensino acadêmico. A bibliografia, no Brasil, sobre estas atividades ainda é escassa. O conhecimento era, e ainda o é, adquirido devido um interesse pessoal e longo acompanhamento da atividade em uma dedicação de tempo, paciência e atenção, como um pupilo que segue os ensinamentos de um mestre. (Godois, 2011, p. 84)

\section{Como se tornou um iluminador ${ }^{4}$}

Carlos Falcão, em entrevista para minha dissertação de mestrado, comentou como se transformou e se formou iluminador:

Em junho de setenta e nove, isso, aí eu posso relatar o acontecimento, é que eu estava na instaladora Santa Rita de Florianópolis e o Diretor do Teatro Álvaro de Carvalho, o Hamilton Faversani, estava comprando umas lâmpadas, e eu como conhecia o Hamilton antes de entrar no teatro, disse que gostaria de trocar essas lâmpadas que ele estava comprando, ele falou para mim aparecer no teatro e simplesmente eu fui ...

Quando estava desempenhando esta atividade de troca das lâmpadas nas luminárias que davam claridade na entrada e na plateia do teatro um incidente vai colocá- lo na rota da iluminação cênica. No dia 05 de julho de 1979 apresentava-se na casa o espetáculo Alta Rotatividade com o ator Agildo Ribeiro e o transformista Rogéria. O técnico de iluminação Carlos Morais, por motivos não esclarecidos nesta pesquisa, desentendeu-se com a direção do TAC e abandonou o posto na véspera da apresentação do espetáculo.

[...] quem estava trabalhando, o irmão do Cláudio (Morais), era o iluminador do teatro, na época [...] e houve algum, alguma coisa que não deu certo e ele foi embora e ficou sem ninguém aqui, até então eu estava começando a colocar as lâmpadas no lustre, e o Hamilton perguntou se eu faria a iluminação, e eu disse simplesmente que faria, e até então eu nunca tinha feito iluminação. Quer dizer, criei a coragem em dizer que faria e fiz.

Falcão precisou improvisar e aprender rapidamente em que botão acionar para a luz produzir efeito. Antes teve de executar ou montar a luz, colocar os projetores nas posições conforme o planejado. Como tinha algum conhecimento básico em eletricidade, fato advindo dos três anos na universidade, não foi muito difícil dialogar com o manuseio dos equipamentos técnicos em iluminação. O mais difícil, segundo

${ }^{4}$ A fonte deste subitem - Godois, 2011, p. 108-109. 
ele, foi operar a luz, pois teve que se agarrar em muita habilidade e improviso para assimilar a sequência de acionamento dos botões de operação. Teve poucas horas para receber as instruções e as deixas, pois o espetáculo dependia de musicas para ocorrerem as mudar de cenas.

O espetáculo já tinha vindo, já tinha orientado a iluminação em si, eu apenas executei, agora acontece que não tinha ninguém para fazer os passos, o profissional para fazer os passos, ai eu tive que fazer, escutar toda a música do espetáculo antes, ai era música... americanas e eu tive que saber qual era, ai tinha as orientações, a musica tal é, ai são dois minutos e ai eu olhava assim no relógio, puxa, dois minutos a tinha a luz tal, ai eu entrava com a luz, já tinha um roteiro por escrito né, e fiz, no ouvido o tempo que era necessário para executar o trabalho.

Este fato não foi o único no inicio da carreira de Carlos Falcão, sua aprendizagem na área de iluminação veio de aposta em sua criatividade e ousadia para desempenhá-la, pois teve que ser instrutor de si mesmo e apoiar-se no conhecimento elétrico que dispunha. No espetáculo Motel Paradiso, de Juca de Oliveira, o iluminador da peça teve um mal súbito e não pode acompanhar as apresentações em Florianópolis. E mais uma vez a habilidade de Falcão teve que vir a tona. As instruções de mudança de luz ou diminuição de intensidade foram-lhe passadas pelo telefone de serviço por uma pessoa que estava posicionada nos bastidores do palco e ele, na cabine localizada na galeria, acima dos camarotes, realizou toda a operação da luz. A aprendizagem na área de iluminação que Falcão teve, no inicio da sua carreira, foi como se diz em uma linguagem popular, de "supetões". Contou muito com a sua intuição, conhecimento elétrico e muita força de vontade, criatividade além da necessidade financeira que tinha em manter-se no emprego para poder frequentar a faculdade.

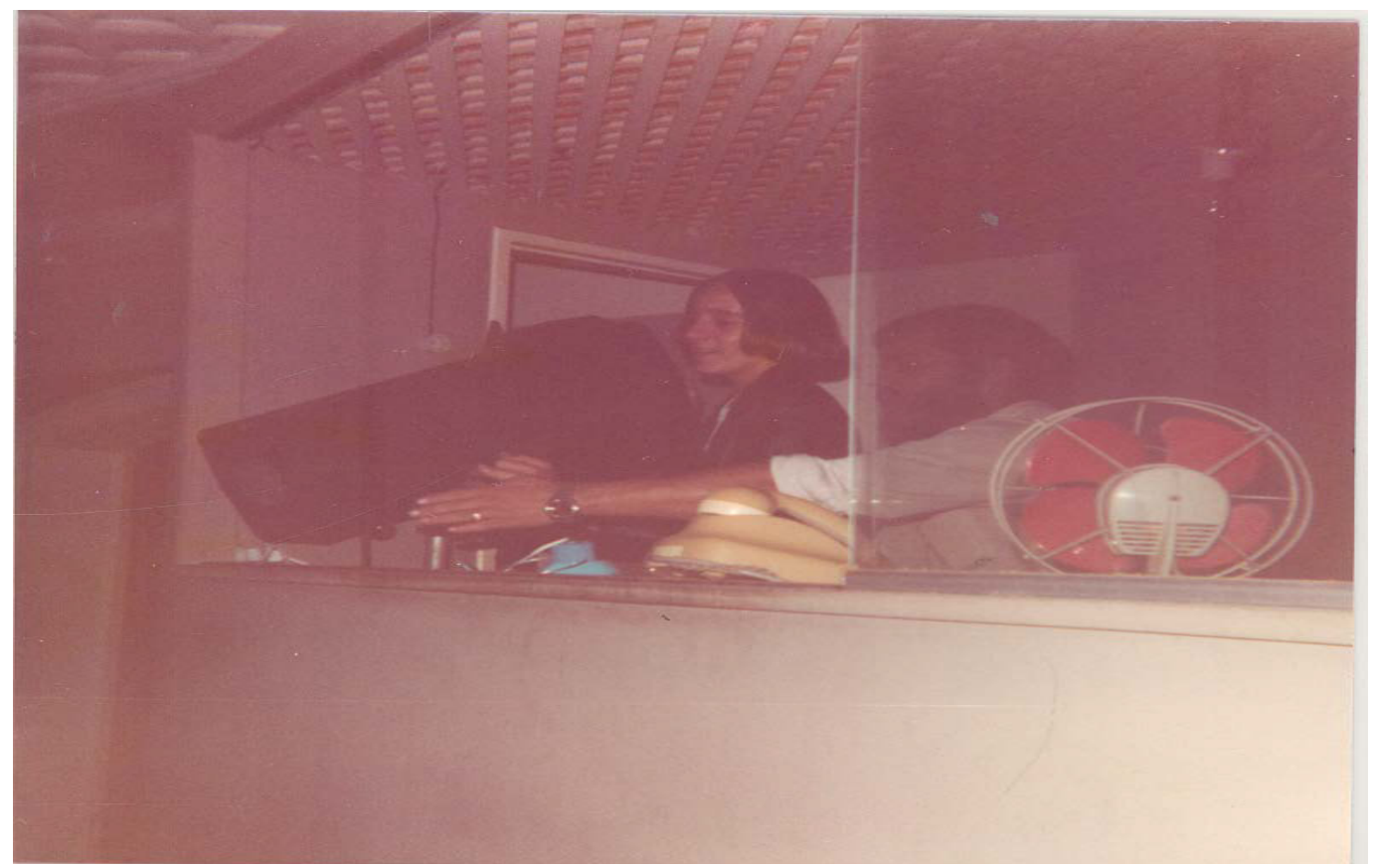

Renato Conrad, no inicio de sua carreira, manuseia um canhão seguidor direcionando-o para o palco, sob a orientação de Carlos Falcão, dentro da cabine de operações técnicas do TAC. Foto: Acervo de Renato Conradi. (Godois, 2011, p. 114)

\footnotetext{
3 Gernot Böhme, The art of the staged set as a paradigm for an aesthetics of atmospheres. http://ambiances revues.org/315. Consulta em: 2 dez. 2017.

${ }^{4}$ Gernot Böhme, The art of the staged set as a paradigm for an aesthetics of atmospheres. http://ambiances revues.org/315. Consulta em: 2 dez. 2017.
} 


\section{Quando e como você iniciou na área de iluminação cênica?}

A lluminação cênica em si, quando entrei no Teatro Álvaro de Carvalho, em junho de 1979.

\section{E como é que foi?}

Foi quando eu vi aquela mesa que instalaram no Teatro Álvaro de Carvalho, e quando eu vi, aquilo mexeu comigo, no meu interior, e eu falei: poxa é isso que eu quero! E como eu sabia levantar os botões [...]. Foi assim que eu comecei, eu tinha conhecimento de eletrotécnica, então eu comecei a ter as ideias de fazer uma luz aqui, colocar um foco aqui e fui aprendendo [...] foi o começo.

\section{E o que você conhecia até então sobre eletricidade, sobre iluminação?}

Sobre eletricidade eu tinha conhecimento, eu não tinha sobre cênica.

\section{E como você tinha esse conhecimento de eletricidade antes de entrar no te-} atro?

Na própria marinha eu fiz curso de eletrotécnico, então eu comecei a fazer a colocação dos refletores, não dos refletores em si, porque na verdade eu não mexia nos refletores, eram nas lâmpadas. Nas posições das lâmpadas, porque na verdade não se fazia a parte cênica. Eu só tinha ideia...

\section{E o que você fazia lá na marinha, nesses trabalhos de elétrica?}

Nós consertávamos as lâmpadas. Os refletores de luz, apenas a elétrica.

\section{Os que tinham no navio?}

Isso, a gente trabalhava na praça de máquinas, em vários setores. O navio é muito grande. Mas a palavra "cênica" em si eu não tinha conhecimento.

\section{Até entrar em 1979 no teatro Álvaro de Carvalho...}

Sim, ali eu comecei a me detalhar sobre essas coisas, situações. Daí entrei no teatro e comecei mais ainda...

E o que te motivou a continuar a trabalhar nessa área de iluminação cênica no Teatro Álvaro de Carvalho?

O motivo eu não sei explicar exatamente, eu só sei que era aquilo que eu gostaria de fazer, apenas isso. Não tem algo que chama mais a atenção. Eu sempre gostei de fazer isso. Eu não sei explicar, não tem motivo, eu só quero é iluminar e ver o resultado... As pessoas aplaudindo, poxa eu fiz aquilo, que legal.

Qual foi a forma que você encontrou para continuar estudando sobre iluminação cênica?

Acho que foi a união das coisas, porque na verdade você está fazendo a parte técnica e para aprimorar você tem que saber que botando o projetor em uma posição diferente você consegue outro trabalho. E foi nesse sentido. Porque a tecnologia veio 
com tudo e você vai ter que lutar para se defender. Se essa cor é boa ou não, você olha. Eu batalhei para me aprimorar, eu queria que desse certo as coisas.

Como e por quanto tempo você conseguiu conjugar a faculdade de Engenharia Elétrica, da UFSC, e o trabalho no TAC, o que isso te ajudava?

Eu não terminei a minha faculdade, isso me doeu. Mas, eu só saí, na fase que tinha que decidir os horários... [ Falcão cursou até o terceiro ano da Engenharia Elétrica da UFSC]. E eu não podia perder meu serviço. Então eu não terminei, eu não podia perder o meu serviço. A aula era muito cedo e não deu para terminar. Eu não estava conseguindo definir a faculdade (grade de disciplinas), tinha a fase de estágios, eu não cheguei na fase profissionalizante, que tinha que fazer projetos... Tinha o problema financeiro e outras coisas todas. Mas foi gostoso, pelo menos eu peguei a parte técnica em eletricidade. Porque eu tinha o conhecimento básico.

\section{E na década de oitenta, existiu algum curso, você chegou a fazer alguma coisa fora de Santa Catarina?}

Sim, fiz. A Fundação Catarinense de Cultura me mandou para o Rio de Janeiro no Centro Técnico de Artes Cênicas. [Neste curso, Falcão teve contato com Aurélio de Simoni]. Eu fiz um curso de iluminação cênica, presenciei montagens. Inclusive tinham grupos de Florianópolis como a Carmem Fossari. Foi ali que eu tive o conhecimento do cênico. Foi muito bom, inclusive eu, o Osni Cristóvão e outras pessoas já fizeram (curso no CTAC).

Nesse início teve algum trabalho de iluminação que te chamou muito a atenção?

Sinceramente não. Eu lembro das pessoas como o Aurélio de Simoni ${ }^{5}$, Gean Carlos $^{6}$, pessoas que vieram à Florianópolis. E também o responsável do teatro Hamilton Faversani [Diretor do TAC na década de 1980].

\section{E o Gean Carlos trouxe algum equipamento? Você lembra de alguma coisa?}

Lembro! O sapão [PC antigo] que tinha uma lâmpada com quase dois palmos que ficou por muito tempo, até a chegada da lâmpada PAR ${ }^{8}$. A lâmpada PAR era totalmente novidade na época.

\footnotetext{
${ }^{5}$ Carioca nascido em 1948, foi, junto com Jorge de Carvalho Moreira (carioca-1946) e Luiz Paulo Nenen (paulista-1957), o "pai" fundador da luz artística no teatro brasileiro, e que exerceu influencia direta nos profissionais da luz em Santa Catarina, através de sua passagem como iluminador de espetáculos pelo Teatro Álvaro de Carvalho, na década de 1980. Aurélio de Simoni esteve no TAC em 1982 com o espetáculo Sonho de uma noite de Verão, e m 1987, no Teatro Ademir Rosa (CIC), com a luz de Fedra, com interpretação de Fernanda Montenegro e Edson Celulari.

${ }^{6}$ Gean Carlos Bortoloto, italiano radicado no Brasil, em São Paulo (SP), empresário com uma "empresa especializada em equipamentos de iluminação, a GCB". (Godois, 2011, p. 97)

${ }^{7}$ Os modelos encontrados no Teatro Álvaro de carvalho na década de 1980 eram: O "PC" no formato arredondado e, devido às frestas de ventilação interna dava a impressão de ser um grande sapo malhado de casca grossa, portanto na época e até os dias atuais este modelo arredondado é chamado de "sapão". (Ivo Godois, 2011, p. 77)

8 A lâmpada PAR 64 foi introduzida no TAC por Beto Bruel, iluminador, residente em Curitiba (PR) que veio à Florianópolis para fazer a iluminação cênica de Zumbi, do grupo catarinense Armação, com direção de Oraci Gemba, também residente em Curitiba, em agosto de 1982. A estreia foi no Teatro Álvaro de Carvalho. Falcão complemento a informação dizendo: Beto Bruel que era dono da empresa Tamanduá. Os equipamentos da empresa complementaram a carência do TAC e as necessidades do espetáculo. Informações obtidas em: (Ivo Godois, 2011, p. 87 a 82)
} 


\section{E mesa de luz não foi Bruel quem não trouxe?}

[Sim] aquela inglesa, strange light, que está lá no teatro [TAC] inclusive.

Como foi seu contato com o Beto Bruel e a empresa Tamanduá de Curitiba? Por exemplo durante a montagem com o espetáculo Zumbi do grupo Armação em 1982 no TAC.

A empresa Tamanduá tinha toda uma estrutura necessária de teatro, então eles me mostraram muita coisa. O espetáculo era difícil e para operar foi mais complicado. Tivemos que usar duas mesas de luz, o Beto Bruel ${ }^{9}$ ficou em uma mesa e eu fiquei na outra. O meu começo foi com eles, o Beto trouxe os equipamentos lá de Curitiba e juntamos com o pouco que nós tínhamos, ah nem se falava em elipso... A gente só tinha os da GCB. E depois nós viajamos com esse espetáculo, o que foi mais difícil, chegamos em lugares que não tinham nada aqui (em Santa Catarina) no interior, mas conseguimos fazer.

E assim você foi aprendendo com ele, com esses nomes que vinham à Florianópolis, com o curso técnico no Rio de Janeiro... O pessoal da GCB. Mas, o Gean Carlos vinha com espetáculos?

Não, ele vinha especialmente quando tinham problemas nos dimmers. Quando tinham queimado. Ele mostrava como era que se concertava, para não precisar ele vir de São Paulo para Florianópolis, e isso favoreceu para gente.

Além do Teatro Álvaro de Carvalho, quais outros espaços você já trabalhou e/ou percorreu com espetáculos?

No estado, o primordial para mim é o Carlos Gomes (Teatro de Blumenau).

Conte-nos um pouco mais sobre o Festival Universitário de Teatro de Blumenau. Como foi que você chegou ao festival?

O contato foi através da professora Terezinha. Onde ela pediu para a Fundação Catarinense de Cultura a ajuda de um técnico, então foram eu e o Osni (Cristóvão) para acompanhar as montagens. E assim fazem trinta anos. Quando chegamos lá nem tinha refletor, eu consegui oito refletores emprestados para levar, refletores pessoais.

Então foram com esses oitos projetores que vocês iniciaram o festival Universitário de Blumenau?

É... Foi o início... Depois foi aprimorando. Fazer uma iluminação com oito refletor foi meio complicado.

Tem algum espetáculo do qual você lembra de ter ajudado a criar a iluminação?

Lembro da Franklin Cascais, era das bruxas. Ah o (Valmor) Nini Beltrame com um

9Luiz Roberto Bruel (Paraná-1950), iniciou “sua carreira como iluminador em 1971 no Teatro Guairá, de Curitiba/PR". (Godois, 201, p. 94) 
espetáculo que estava no exterior, mas o nome me fugiu. ${ }^{10}$

E como foi o seu contato com a Universidade do Estado de Santa Catarina (UDESC), com o curso de Artes Cênicas? Porque você também trouxe algum conhecimento e ajudou no início a construção do laboratório de iluminação...

Foi um auxílio para a Vera Collaço, eu lembro de oito refletores que ela conseguiu comprar, assim eu vim montar, conheci a sala. Eram refletores de quinhentos, nós não tínhamos de mil watts ainda. É uma diretora que não mede esforços, dedicada, perfeita. Foi onde tudo começou.

Eu sei que eles compraram equipamentos e você ajudou a instalar, eram mesa e equipamentos GCB.

Sim, era GCB. Era o básico, porque até então a gente fazia iluminação com teclas (fabricação artesanal). Eu fiz uma mesinha de tecla, de nove refletores para poder iluminar o espetáculo. Isso eu lembro como se fosse hoje. Era uma mesinha de tecla da PIAL, eu fiz nove espaçozinhos (tomadas de conexão) para poder plugar esses refletores que foram adquiridos.

Qual era o método e as pessoas que fizeram parte de um princípio de aprendizagem com você? Como você comungava esses conhecimentos? Seja no Festival de Teatro de Blumenau ou no TAC.

Eu lembro do Irani Brunner Apolinário, Eugenio de Andrade... mas essas pessoas vieram depois. Ah! E o Renato Conradi que era um grande parceiro que iniciou comigo, e ele até abriu uma empresa depois. Ele fazia a sonoplastia e eu a iluminação. E o Irani ajudou na montagem (construção/instalação do sistema técnico do teatro) do $\mathrm{CIC}$ (Centro Integrado de Cultura).

Ivo: Você trabalhou em outro festival pelo estado além do Festival de Teatro de Blumenau?

Falcão: Sim, FECATE [ Federação Catarinense de Teatro Teatro] ${ }^{11}$.

Na década de oitenta você era uma pessoa que trabalhava em um teatro que tinha um pouco de recurso, como era que você compartilhava essas experiências adquiridas com o pessoal do estado que vinham procurar informações sobre iluminação?

Como eu falei, eu ensinava não como um professor. Eu ensinava a montar, mas o meu conhecimento eu não conseguia expor como um professor de universidade.

\footnotetext{
${ }^{10} \mathrm{~A}$ doença e a modéstia não deixaram Falcão se lembrar dos inúmeros espetáculos para os quais criou e executou a iluminação cênica. E também dos inúmeros prêmios que recebeu, em festivais, pela iluminação em diferentes espetáculos catarinenses. Como observei em minha dissertação: Falcão assinou inúmeras montagens locais, e com isso perpassou por diferentes estéticas, estilos diretivos e espetáculos adultos e infantis. Sua formação foi solidificando-se nestas diferentes concepções cênicas e seu nome ganhando projeção em todo o estado catarinense como uma referência sobre iluminação cênica. No ano de 1982, além do espetáculo Zumbi, em outubro ele foi o iluminador de Woyzeck, de Georg Buchner, encenado pela Escola Aberta de Teatro, com direção de Vera Collaço. Uma crítica de Mário Alves Neto colocava: "A coreografia da Martha, a iluminação do Falcão, as melodias do Perrone estão bem de acordo com a ideia geral da montagem. 'Woyzeck' é o melhor espetáculo dos últimos anos, nesta cidade [...]". (Godois, 2011, p. 112)

$11 \mathrm{No}$ ano de 1986 [de] 29 de outubro a 02 de novembro ocorreu, tanto no TAC quanto no CIC, o $2^{\circ}$ Festival Catarinense de Teatro FECATE e o $1^{\circ}$ Festival de Teatro Infantil - FECATI. O evento foi organizado pela Federação Catarinense de Teatro (FECATE), através de seu presidente Edelberto Westphal. Falcão teve [então] contato direto com diretores de teatro catarinense de diversas cidades entre elas, Blumenau, Joinville, Itajaí, Lages, Criciúma, Joaçaba, Chapecó. (Godois, 2011, p. 115)
} 
Porque eu sou aluno também. Eu só falava "coloca assim", "evita de fazer isso pois vai acontecer tal coisa"

Mas o que acontecia era essa troca de conhecimento. Porque a pessoa que vinha como o diretor do espetáculo acabava aprendendo e isso ajudava os grupos a melhorar suas técnicas. E você contribuía com a informação que você tinha na época.

Ah! Sim. Esse termo de compartilhar sim. Essa questão de mostrar a angulação, posição, todos esses conhecimentos que eu tinha da engenharia ajudavam, porque a própria faculdade me ensinou.

Mas você dizia que antes da faculdade você trabalhava no navio, como funcionava essa troca de material no navio?

Essa é outra novela. O que acontece é que no navio eu trabalhava na parte técnica. Eu sempre fui eletricista, na verdade hoje a gente fala eletrotécnico. Então o que acontece é que o eletricista fica de plantão no navio, e no momento que estamos em alto mar e uma lâmpada queimou (externa no navio) em altura máxima, dai você tem de ir lá trocar a lâmpada e para trocar não é por uma grua e levanta. Você tem que ir na escada, lá em cima, com calçado para não cair. Isso aconteceu uma vez quando estava indo para a Argentina, o navio começou a balançar muito e isso era noite, e a lâmpada queimou e se a lâmpada queima é um perigo da outra pessoa perder o

\section{Era uma espécie de farol do navio...}

Exatamente. Um farol. E na hora que ele está apagado ele se torna estranho. Um outro navio pode esbarrar, acontecer um acidente. Então você tem que trocar a lâmpada, então você vai lá em cima, fica dentro de.... quase que uma cesta e tal, na parte de cima do mastro e você tem que trocar a lâmpada. São detalhes que você tem que tomar cuidado. E onde eu fazia essa parte, esse exercício lá em cima. E é um exercício gostoso, saber que tu fizeste aquilo e a lâmpada acendeu depois...

Então essa sua experiência com o navio te ajudou bastante depois no teatro?

Com certeza. Você já entra sabendo, parece incrível. Na hora que eu entrei para o teatro, foi por isso que quando eu entrei e vi o teatro, eu vi e disse é isso que eu quero. Por que na verdade foi uma oportunidade daquilo que eu tive, eu comecei com dezessete anos. E quando eu saí da marinha, eu fiquei dez anos (na marinha), e na hora que eu saí... o que é que eu ia fazer? Vou fazer alguma coisa de teatro. Quando cheguei no Teatro Álvaro de Carvalho parecia que eu não saí, eu mudei, eu estava ali e mudei para lá. E foi assim que eu me senti (e até hoje).

\section{E qual o conselho que você daria para os iniciantes da área hoje?}

Primeiro passo é estudar, isso aí é básico, todo mundo é obrigado a estudar, não pode ficar a ver navio. Se não a vida passa e você se perde. E outra coisa, é que na realidade eu errei muito; o tratamento, você ficar nervoso, você não pode ficar nervoso e esse detalhe tem que passar para as pessoas, tem que manter a calma, 
porque a gente fica muito... quer tudo pronto na hora, primeiro é que não pode ser tudo pronto na hora, porque tudo tem tempo, se não der tempo ao tempo as coisas não acontecem. E outra coisa, se tem que fazer alguma coisa, tem que ter responsabilidade de horário. Infelizmente, o pessoal de artes cênicas não está fazendo isso, está nos machucando. Estou querendo falar que no teatro tem que ter pontualidade. É como se fosse igual ao inglês (pontualidade inglesa) é aquela hora e sim, porque a palavra 'depois' eu tenho pavor. Os "depois eu faço" machucam as pessoas. Naquele momento, as coisas quando acontecem são naquela hora. Porque os acidentes acontecem! São os deixar para "depois" que geram acidentes.

O grande acidente (Um choque elétrico) que eu tive foi para economizar altura. Porque essa cadeira é melhor, essa cadeira é pior, eu estava em uma cadeira além do normal, que estava alta e eu fui assumi um negócio que não era culpa minha, que foi desligar um interruptor que o cara tinha dito que tinha desligado, e na hora estava ligado. E eu ao invés de verificar, não verifiquei. Então na hora que deu o acidente o que eu fiz para evitar a situação maior, eu virei a mão para não cair, e na hora que eu ia caindo a cadeira perdeu o equilíbrio. Então foi isso que aconteceu e graças a Deus estou aqui, porque naquela hora foi complicado, fiquei caído no chão. E ali (com o choque) a língua começou a enrolar, parece um negócio incrível, que a língua ela enrola cada vez mais, você quer falar e não dá. Um trauma que eu tenho, que está dormente até hoje. Mas graças a Deus eu estou falando, eu nem falava, no começo foi difícil, mas hoje está tudo bem, fico mais dez anos, quinze anos sem problemas.

\section{Como é quando você vê essa meninada nova chegando lá no teatro que você} já está há um bom tempo?

Eu vejo feliz, eu vejo feliz. Porque as pessoas que estão entrando... estão entrando bem, sabe? Inclusive, eu estou querendo estudar mais, querendo aprimorar. Porque com esse rolo todo, para evitar o conhecimento, eu falei então: Vou para o maquinário. Porque no maquinário você precisa levantar a corda, o peso.

\section{Te lembrava o navio?}

É, talvez, talvez. Então o que está acontecendo, eu estou no Teatro Álvaro de Carvalho, mas eu estou na parte do maquinário. Mas, eu estou namorando a mesa (de luz), eu vou lá em cima e fico olhando, vejo como é. Porque a tecnologia chegando quebrando tudo. Você tem que saber como é, o refletor assim, o ângulo assim e você vai aprimorando. Na verdade, eu estou voltando a aprender, querendo aprender. $E$ o mais importante! Eu não quero ir embora. Estou com vontade de ficar mais ainda, mas tem o limite que é obrigado a sair dai...

Você gostaria de deixar mais algum recado? Existe alguma coisa mais que que você gostaria de falar sobre iluminação?

A grosso modo, eu posso ter esquecido, eu não lembro exatamente. Muitas coisas eu esqueci de lembrar agora. Eu gosto muito do que eu faço, o mais importante é que eu gosto muito do que eu faço. Eu trabalho por amor, não é amor, é AMOR. 
Sabe? É um carinho de fazer as coisas assim, eu gosto. Logicamente dizer que não precisa de salário... Precisa de salário sim. Tá feio o negócio.

Muito obrigado Falcão.

Recebido em: 02/04/2018

Aprovado em: 02/04/2018 